\title{
TRADUÇÃO E INTERPRETAÇÃO DE LÍNGUA DE SINAIS (TILS) NA PÓS-GRADUAÇÃO: A AFILIAÇÃO AO CAMPO DISCIPLINAR “ESTUDOS DA TRADUÇÃO”»
}

\author{
Maria Lúcia Vasconcellos \\ Universidade Federal de Santa Catarina \\ marialuciabv@cce.ufsc.br
}

Resumo: Este trabalho sugere a afiliação das áreas de pesquisa "Tradução" e "Tradução e Interpretação de Línguas de Sinais" (TILS) ao campo disciplinar Estudos da Tradução (ET) o qual,a partir de seu estabelecimento na década de 70 , tem se expandido em resposta à diversidade na investigação de línguas e culturas em contato via tradução, inclusive entre modalidades diferentes, como é o caso de línguas orais e línguas de sinais. Nesse contexto, apresenta, inicialmente, um mapeamento dos "Estudos da Tradução" no cenário internacional e nacional para, a seguir, mostrar, por meio da apresentação dos desdobramentos recentes, como a pesquisa em TILS tem sido reconhecida como área de ET. Na Pós-Graduação, a pesquisa em TILS é evidenciada pelo surgimento de teses e dissertações em diferentes programas no contexto internacional. Reflexões finais reafirmam a sugestão da afiliação estratégica do pesquisador/profissional de TILS aos Estudos da Tradução, considerando que tal afiliação, longe de obscurecer a especificidade identitária de tal profissional, pode contribuir para o fortalecimento de seu empoderamento e visibilidade.

Palavras-chave: tradução e interpretação de línguas de sinais (tils), campo disciplinar 'estudos da tradução', pós-graduação no Brasil.

\begin{abstract}
This paper posits an affiliation of the research areas "Translation" and "Translation and Interpretation of Sign Languages" (TILS) to the disciplinary field "Translation Studies" (TS,) which, from its establishment in the early seventies, has been in constant expansion in response to the diversity of investigation of languages and cultures in contact via translation, including those between different modalities as is the case with oral and sign languages. In this context, it first maps TS in both
\end{abstract}


international and national contexts in order to show through a review of the more recent developments in the field how research in TILS has been accepted as a specific area in TS. At graduate level, this development is clear from the number of theses and dissertations defended at various graduate programs internationally. Final considerations reaffirm the idea of affiliating TILS professionals with TS, as this affiliation - far from blurring the boundaries of professional identity specificity - can contribute to its confirmation and to the empowerment and visibility of the TILS community

Keywords: sign language translation and interpretation (TILS), translation studies area, brazilian graduate program.

\section{Introdução}

O tema do I Congresso de Pesquisa em Tradução e Interpretação de Línguas de Sinais $^{2}$ evidencia a pouca atenção dispensada aos profissionais de Tradução e Interpretação de Língua de Sinais (TILS) no espaço universitário, sinalizando, a necessidade de intercâmbio acadêmico entre TILS e "diferentes áreas do conhecimento" Em uma primeira leitura, causa estranheza a inclusão da tradução entre as chamadas "diferentes áreas de conhecimento’. A colocação da tradução nesses termos, no primeiro Congresso Brasileiro de TILS, ressalta a questão identitária dos profissionais dessa área como prioridade estratégica, o que, legitimamente, poderia demandar um espaço acadêmico diferenciado. É nesse contexto que trago minha reflexão, uma vez que faço parte dos "acadêmicos interessados em consolidar, na Universidade Federal de Santa Catarina, o espaço acadêmico da pesquisa em interpretação e tradução de Língua de Sinais na Pós-Graduação", conforme formulação constante do programa do evento.

Mesmo levando em conta a legitimidade da questão identitária da pesquisa em TILS, pretendo sugerir que: (i) 'Tradução’ 
e 'Tradução e Interpretação de Línguas de Sinais' podem beneficiar-se da filiação a um mesmo campo disciplinar - Estudos da Tradução (ET) - que, a partir de seu estabelecimento na década de 70 (época em que a comunidade científica reconhece como marco fundacional do campo disciplinar o texto escrito por Holmes, em 1972), tem se expandido em desdobramentos amplos o suficiente para acolher as diversidades das manifestações de estudos sobre línguas e culturas em contato; e (ii) o campo disciplinar ET pode acolher investigações em interfaces que exploram o contato entre línguas de modalidades diferentes (línguas orais e línguas de sinais), tanto em termos lingüísticos, quanto em termos culturais e políticos. A inserção estratégica do tradutor e do intérprete de línguas de sinais em um campo disciplinar já estabelecido, longe de diminuir a importância de sua questão identitária, pode contribuir para o fortalecimento do empoderamento ("empowerment") ${ }^{3}$ desses profissionais que, mesmo filiados a um campo disciplinar já constituído, não perdem sua especificidade ou visibilidade.

Para desenvolver meu argumento, organizo o artigo nas seguintes subseções: inicialmente, apresento um mapeamento da constituição do campo disciplinar "Estudos da Tradução" (no contexto internacional e nacional) para, a seguir, mostrar, por meio da apresentação de desdobramentos recentes, como a tradução e interpretação de TILS tem sido reconhecida como subárea de ET; a seguir, discuto a inserção de TILS na pesquisa na Pós-Graduação (surgimento e distribuição de teses de Doutorado, dissertações de Mestrado e trabalhos de conclusão de cursos) no contexto internacional; a partir daí, apresento reflexões finais em que, mesmo reconhecendo a natureza problemática da filiação em termos da questão identitária, reafirmo meu argumento pela inserção estratégica de TILS em ET, sobretudo na pós-graduação brasileira. 


\section{Mapeamento do campo disciplinar "Estudos da Tradução"}

Inicialmente, cumpre definir a expressão 'campo disciplinar' e o significado de se mapear a constituição de um campo disciplinar específico. Em sua dimensão lingüística, a expressão 'campo disciplinar' é formada por um grupo nominal que apresenta a noção de 'disciplina', termo derivado do grego 'Maqhma' (ciência e aprendizagem), em combinação com a noção de demarcação de um 'campo' ou 'território' próprio de tal disciplina, no âmbito do qual são definidos parâmetros, conceitos, limites e um repertório determinado de conhecimento passível de ser construído, aprendido, ensinado e modificado (Vasconcellos \& Bartholamei, 2008). Fazer um mapeamento de um campo disciplinar significa, então, estabelecer os contornos e identidades de um conjunto de conhecimentos específicos, desenhando sua trajetória desde a origem e institucionalização, até os desdobramentos atuais, coloridos por suas interfaces com outras disciplinas e práticas afins.

Para discutir mapeamentos do campo disciplinar "Estudos da Tradução", cumpre fazer uma distinção entre tradução e/ou interpretação como atividade prática e Estudos da Tradução como campo disciplinar. A tradução/interpretação enquanto prática é uma atividade que existe 'desde sempre'. Não se sabe quando a primeira tradução foi feita, mas, com certeza, ela se deu em tempos imemoriáveis, sempre que povos, culturas e línguas diferentes estiveram em contato. Tal característica de "existir desde sempre" pode ser aplicada a outras áreas do saber. Por exemplo, no campo disciplinar, hoje conhecido como ARQUITETURA, as atividades artísticas sempre foram exercidas pelo artesão, no contexto de uma prática técnica e 'oficional'. Com o passar do tempo, esse artesão se transformou no profissional 'arquiteto' e as artes desse ofício foram, lentamente, se consolidando como um agrupamento moderno de artes, passando a constituir a forma estabelecida do Campo Disciplinar da Arquitetura. Conforme Brandão (2005), o campo 
disciplinar da arquitetura não foi propriamente inventado e intencionalmente proposto, mas construído lentamente, à medida que a prática técnica e 'oficiosa' ganhou uma dimensão intelectual, ou seja, o 'fazer' passou a ser acompanhado do 'pensar sobre o fazer'. Em outras palavras, o campo disciplinar passou a se constituir como tal, quando aconteceu uma investida teórica e institucionalizada à prática da atividade específica.

Um processo similar ocorreu com a tradução: as atividades de tradução e interpretação sempre foram exercidas por indivíduos na função de mediadores em interações em que a barreira lingüística impediria a comunicação, seja de textos escritos ou textos orais, no contexto de uma prática oficiosa. Com o passar do tempo, esses tradutores e/ou intérpretes se transformaram no profissional 'tradutor/intérprete' e as artes da tradução/interpretação foram, lentamente, consolidando-se como um conjunto de competências passíveis de ensino/aprendizagen, passando a constituir o ramo aplicado do campo disciplinar hoje conhecido como Estudos da Tradução. Tradutores e intérpretes têm traduzido desde sempre. Como nos lembram Guerini e Costa (2008), a tradução é uma atividade antiga e já foi descrita na Bíblia. "No Brasil", continuam os autores (ibid.), "calcula-se que a tradução interlingual representa cerca de 60 a $80 \%$ dos textos publicados e que $75 \%$ do saber científico e tecnológico provém das traduções, alimentando vários setores da vida nacional. Sem a tradução, muitos setores simplesmente não funcionariam, como por exemplo, os setores de softwares, medicamentos, automobilístico, etc.". Na verdade, essa situação remonta à própria história do país, que é uma história de tradução, como nos conta Barbosa e Wyler, as autoras do verbete "The Brazilian Tradition" (1998). Segundo essas autoras, o primeiro documento oficial sobre o Brasil - a Carta de Pero Vaz de Caminha ao Rei Manuel I - narra o descobrimento de novas terras e registra um ato de tradução: descreve como os portugueses e os "índios" tentavam se comunicar por meio de gestos e como um membro da frota de Cabral, Afonso Ribeiro, foi deixado com os índios para aprender sua língua e, a partir de então, servir como intérprete nas interações. 
Ao longo da história, tradutores continuaram a traduzir e intérpretes a interpretar. Vários deles apresentaram importantes escritos sobre $o$ traduzir e a tradução, refletindo sobre os métodos por eles utilizados, sobretudo e tipicamente, no prefácio de suas traduções. Até a segunda metade do século XX, reflexões sobre tradução em forma de artigo acadêmico eram publicadas de forma aleatória, espalhadas em periódicos dos chamados macro-campos disciplinares já estabelecidos (por exemplo, a Lingüística Aplicada ou a Literatura comparada), ainda não constituindo um conjunto de conhecimentos agrupados num campo específico. O que faltava, então, era a constituição desse campo de estudos como um campo disciplinar institucionalizado, tendo como objeto de investigação a tradução (aqui entendida em seu sentido mais amplo).

Tal situação foi percebida por um pesquisador, Holmes (1972, 1988, 2000), que, em um congresso de lingüística aplicada, sediado em Estocolmo, em 1972, apresentou um trabalho que, conforme mencionado acima, é hoje reconhecido pela comunidade acadêmica como texto 'fundacional' dos Estudos da Tradução: nesse texto, o autor sugeriu um nome para esse campo de investigação científica, a saber, "Estudos da Tradução". O trabalho de Holmes só chegou a ser publicado 16 (dezesseis) anos depois, em 1988. Recentemente, esse trabalho foi incluído entre os textos considerados centrais da área, reunidos em um volume organizado por Venuti, no ano 2000. Holmes propõe um mapeamento do novo campo disciplinar, visualizado na Figura 1. Esse mapeamento da disciplina é aceito como o marco inicial dos Estudos da Tradução, conseguindo organizar - na década de 70 - as atividades acadêmicas na área (ver Baker, 1998:277) e capturar as mais tradicionais vertentes da pesquisa na área; a distinção por ele proposta entre estudos aplicados (voltados para a prática) e estudos puros (estudos teóricos e descritivos) e suas subseqüentes divisões servem de norteamento para a pesquisa de tradução. Vale observar que a formulação de Holmes não pressupõe compartimentos e categorias estanques, como a Figura 1 abaixo poderia sugerir; ao contrário, Holmes deixa claro que essas ramificações se alimentam mutuamente, em uma relação dialética. 
O mapeamento de Holmes para o novo campo disciplinar é visualizado na Figura 1:

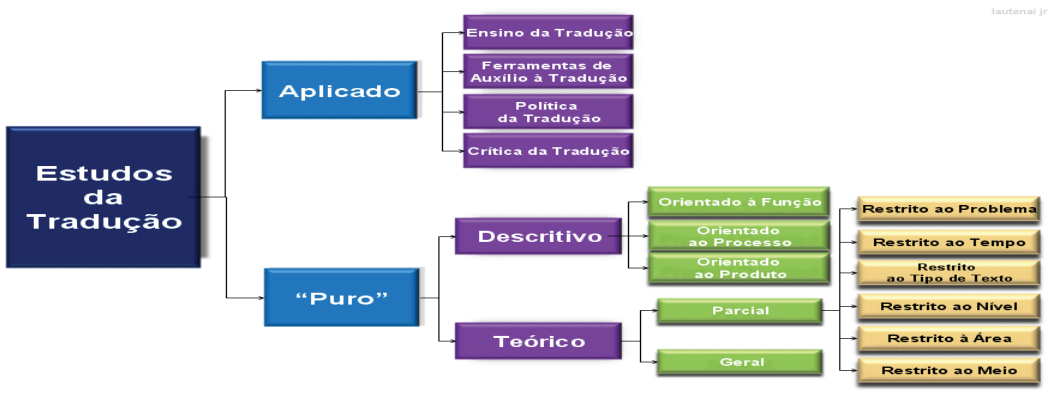

Figura 1 - Mapeamento da Disciplina de Estudos da Tradução de acordo com Holmes (1972/1988/2000)

A proposta de Holmes é historicamente datada, razão que explica o fato de a Figura 1 não mencionar muitos dos tipos de pesquisa em Estudos da Tradução realizados na atualidade, como por exemplo, estudos baseados em tecnologia (tradução apoiada por computador), ou mesmo a interpretação, em quaisquer modalidades, seja em língua de sinais ou não. Na década de 70, as tecnologias não estavam ainda desenvolvidas e o ofício de intérprete não tinha, ainda, se institucionalizado de forma a merecer a atenção dos pensadores da área. No entanto, algumas décadas depois, novos mapeamentos surgiram, representando novas possibilidades de subáreas de pesquisa, sequer vislumbrados no trabalho de Holmes. Por exemplo, o mapeamento feito no contexto brasileiro, por Pagano e Vasconcellos (2003), a partir de pesquisa em universidades públicas e particulares, mostra claramente novos desdobramentos surgidos sob a denominação geral "Estudos da Tradução". ${ }^{4}$

Para o estudo feito no Brasil (Pagano \& Vasconcellos, 2003), como fonte de dados, foram cadastrados um total de 95 (noventa e cinco) resumos, incluindo-se trabalhos de mestrado, doutorado e livre-docência, levantados em diferentes Instituições de Ensino Superior (IESs) no Brasil (4 universidades federais (UFMG, UFSC, 
UFRJ e UFRGS), 4 universidades estaduais (USP, UNICAMP, UNESP (campi Rio Preto e Araraquara) e UECE) e 3 universidades católicas (PUC-SP, PUC-RIO e PUC-RS)). No corpus assim criado, abrangendo o período de 1980 e 1990, emergiu uma concentração majoritária de pesquisa se deu em nível de mestrado, com 54 dissertações registradas, isto é, $56,8 \%$ do total. No entanto, o número de teses de doutorado, 39 , isto é $41,1 \%$, revela-se também bastante significativo. Tendo-se em vista o estágio embrionário dos Estudos da Tradução no Brasil nas décadas em questão, esperarse-ia um número de teses de doutorado bem inferior. Todavia, a grande expansão dos Estudos da Tradução no contexto internacional nas décadas consideradas parece ter tido uma repercussão direta no Brasil. Por outra parte, a pouca freqüência de teses de livre docência está relacionada com o fato de ser esta uma modalidade demandada por carreiras docentes apenas em algumas poucas instituições no país.

Como mostra a Figura 2, abaixo, enquanto grande parte da pesquisa em tradução no Brasil na década estudada enquadra-se no arcabouço proposto por Holmes, uma significativa porção ultrapassa o desenho original. No 'mapa' brasileiro, surgem os chamados Estudos Intersemióticos (sobretudo relacionados a traduções de romances para teatro); no ramo aplicado da disciplina, subáreas como 'Tradução e computador'; no ramo descritivo entram em cena os "Estudos baseados em corpus eletrônico", outra novidade não prevista por Holmes, decorrente dos desenvolvimentos tecnológicos. É interessante observar que os estudos de "Interpretação" ainda não se fazem presentes nesse mapeamento de 2003.

O 'mapa' brasileiro é apresentado na Figura 2. 


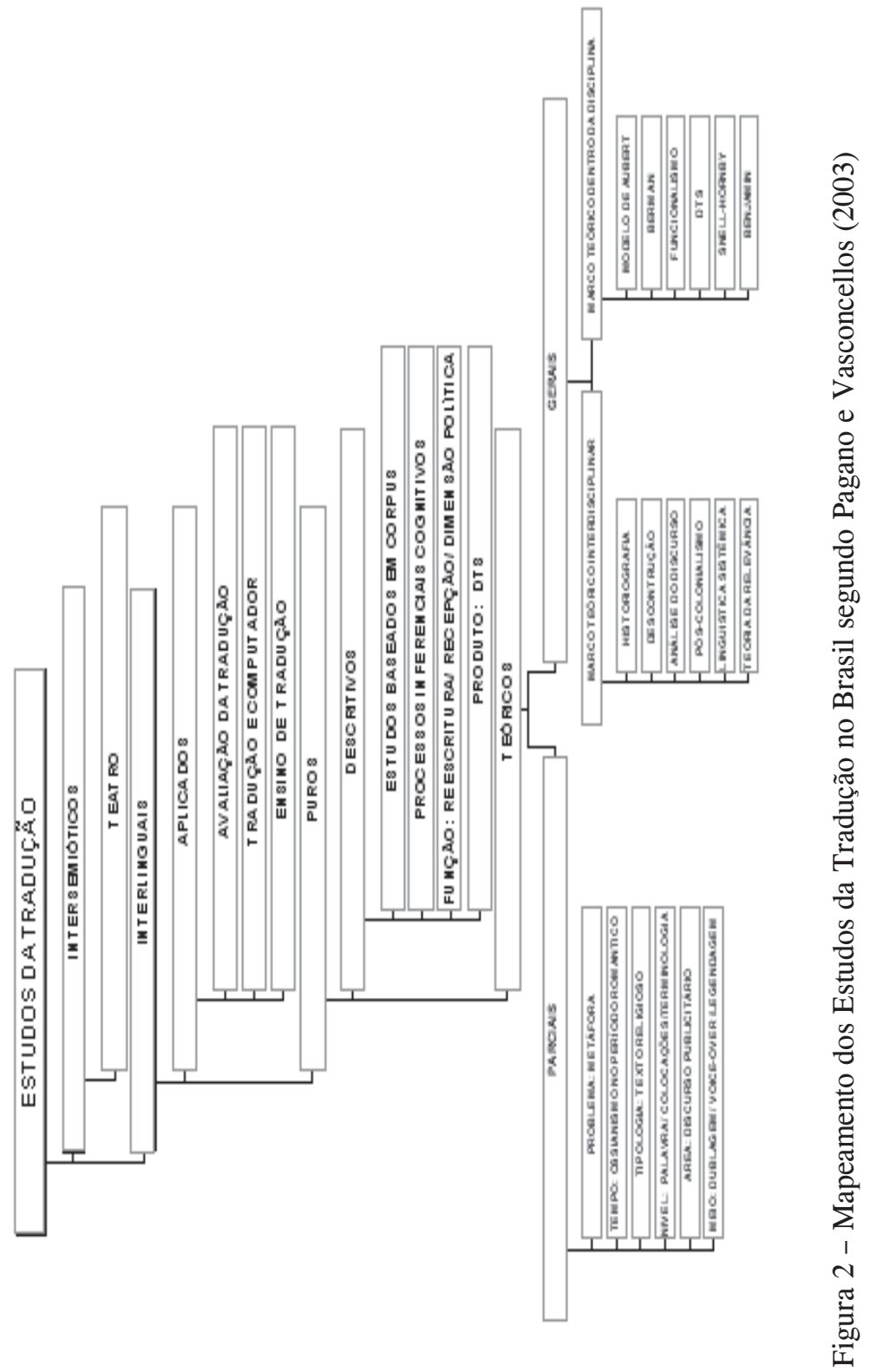


Os desdobramentos do campo disciplinar não param por aí. Novas propostas são sugeridas, em resposta às novas configurações da pesquisa em Estudos da Tradução. A Figura 3 apresenta a proposta de mapeamento feita por Williams \& Chesterman (2002).

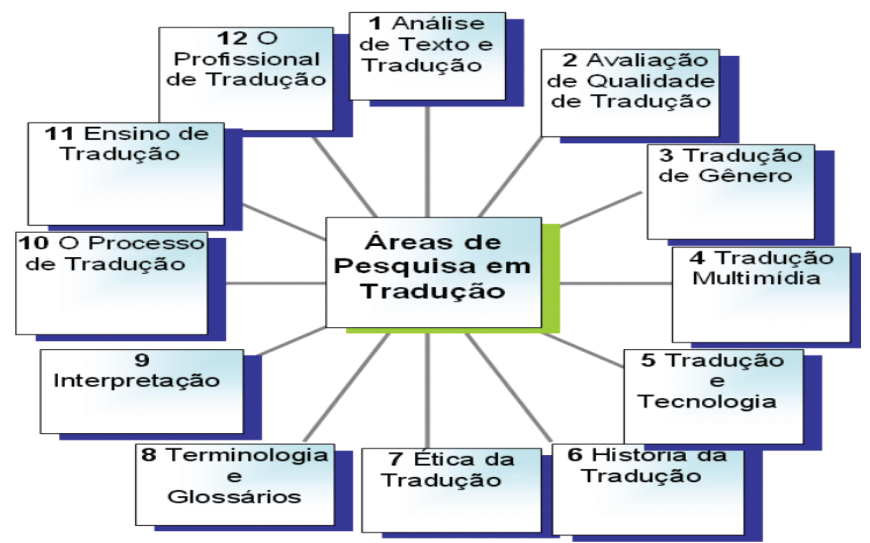

Figura 3 - Mapeamento dos Estudos da Tradução segundo Williams e Chesterman, 2002.

O mapeamento de Williams \& Chesterman (2002) divide o 'território da tradução’ em 12 (doze) áreas, refletindo, de forma mais explícita daquela manifestada no mapeamento de Holmes (ibid.), a natureza interdisciplinar de um campo disciplinar em constante reconfiguração. Esse novo desenho inclui a 'Área 9' - 'Interpretação' - agora estabelecida e consolidada no interior do campo disciplinar Estudos da Tradução. Cumpre observar que, na descrição dessa área, os autores agrupam os diferentes tipos de interpretação em tópicos; um deles - Tipos Especiais de Interpretação - refere-se à interpretação de línguas de sinais e interpretação para surdos, que começa a ganhar visibilidade. Entre o ano da proposta desses teóricos (2002) e a data da pesquisa realizada para o presente trabalho (2009), surgiram novas formas de se investigar o fenômeno da tradução, em suas manifestações cada vez mais variadas e complexas, que são apresentadas a seguir. 


\section{Desdobramentos recentes}

Uma rápida visita ao sítio daquela que é, talvez, a mais importante editora de obras vinculadas aos Estudos da Tradução no mundo ocidental - St. Jerome Publishing ${ }^{5}$ - é suficiente para comprovar que novos interesses emergem no interior do campo disciplinar Estudos da Tradução, adquirindo importância e sendo apresentados como áreas sistematizadas e consolidadas. Ressalta-se a Interpretação de Línguas Sinalizadas ("signed languages") (item 18 da relação que se segue), ramo que passa a constituir uma subárea do campo disciplinar na atualidade. As várias áreas apresentadas no sítio da St. Jerome Publishing, ${ }^{6}$ são listadas a seguir, em tradução proposta por mim, para o português brasileiro.

1. Tradução Multimídia e Audiovisual

2. Tradução Religiosa e Bíblica

3. Bibliografias

4. Interpretação para a Comunidade/ Interpretação de Diálogo/ Interpretação para Serviço Público

5. Interpretação Simultânea e de Conferência

6. Estudos Comparativos e Contrastivos

7. Estudos Baseados em Corpus

8. Interpretação Legal e Jurídica

9. Avaliação /Qualidade /Avaliação /Testes

10. História da Tradução e Interpretação

11. Estudos Inter-Culturais

12. Estudos de Interpretação

13. Tradução Literária

14. Tradução (auxiliada) por Computador

15. Trabalhos de Múltiplas Categorias

16. Estudos Orientados ao Processo

17. Metodologia de Pesquisa

18. Interpretação de Línguas Sinalizadas

19. Tradução Técnica e Especializada 
20. Terminologia e Lexicografia

21. Gênero e Tradução

22. Tradução e Ensino de Línguas

23. Tradução e Política

24. Tradução e a Indústria da Língua

25. Políticas de Tradução

26. Teoria de Tradução

27. Formação de Tradutor e Intérprete

Observando-se essa lista, é possível verificar que os desdobramentos atuais dos ramos dos Estudos da Tradução cobrem um repertório mais amplo de interesses disciplinares e refletem desenvolvimentos recentes, para além das áreas mais tradicionais de pesquisa mencionadas por Holmes (1972/1988/2000). A 'interpretação' - enquanto ramo consolidado dos Estudos da Tradução - surge em 07 (sete) das 27 (vinte e sete) áreas, a saber: (4) Interpretação para a Comunidade/ Interpretação de Diálogo/ Interpretação para Serviço Público; (5) Interpretação Simultânea e de Conferência; (8) Interpretação Legal e Jurídica; (10) História da Tradução e Interpretação; (12) Estudos de Interpretação; (18) Interpretação de Línguas Sinalizadas; e (27) Formação de Tradutor e Intérprete.

Uma comparação dos mapeamentos apresentados permite verificar a trajetória da interpretação em direção a um espaço institucionalizado dentro dos Estudos da Tradução. Vale uma observação com relação à área 18 - "Interpretação de Línguas Sinalizadas".7 Segundo SACKS (1991), uma 'língua sinalizada' se distingue de uma 'língua de sinais' pela estrutura das unidades oracionais. Em uma língua 'sinalizada', os sinais básicos seguem as categorias da língua oral do país/região onde a comunicação ocorre. Essa distinção é apontada no Dictionary of Translation Studies (Shuttleworth \& Cowie, 1997), cujos autores invocam os teóricos Brennan \& Brien (1995, p. 117) para explicar línguas sinalizadas ${ }^{8}$ como "línguas faladas transmitidas visualmente", que se diferenciam de 'línguas de sinais' como sendo línguas que possuem estrutura inde- 
pendente própria, totalmente desenvolvida e que funcionam como a língua nativa ou primeira língua de indivíduos que são surdos de nascença. Assim, enquanto uma língua sinalizada tenta repetir a estrutura de uma língua oral do contexto onde ela é utilizada (por exemplo, a língua portuguesa brasileira), por meio de gestos e sinais que imitam a estrutura da língua oral em questão, uma língua de sinais é uma língua formal e independente, que tem uma estrutura própria.

A sugestão de possível falta de entendimento da distinção por parte da St. Jerome - aparentemente usando "signed language" como sinônimo para "sign language" está baseada em evidência oferecida pela própria editora St. Jerome: embora sua lista de categorias dentro dos Estudos de Tradução tenha mencionado "signed language" (língua sinalizada), esta mesma editora acaba de lançar uma série nova intitulada The Sign Language Translator and Interpreter, cujo volume 1, número 1 foi publicado em 2007 - o que comprova a emergência de um novo ramo de investigação - 'Sign language' e não 'Signed language'. Um dos artigos do volume se refere à Interpretação de Línguas de Sinais ${ }^{9}$ como um território ainda não descrito no mapa. ${ }^{10}$

Em consonância com o contexto internacional ocidental (aqui representado pela St. Jerome Publishing), a área de Interpretação em Línguas de sinais adquire proeminência, no contexto brasileiro, especificamente na Universidade Federal de Santa Catarina (UFSC), enquanto espaço profissional e acadêmico em que o intérprete de Libras adquire uma visibilidade nunca antes institucionalmente percebida. Como ilustração, cito o exemplo da cerimônia da posse do novo Reitor da UFSC, ocorrida em 10 de maio de 2008, para a qual uma equipe de intérpretes de Libras foi solicitada pela reitoria e foi oficialmente apresentada à comunidade pelo Mestre de Cerimônia, que agradeceu publicamente sua participação.

É interessante observar que a área 27 - Formação de Tradutor e Intérprete - se mantém como preocupação do campo disciplinar Estudos da Tradução, que busca desenvolver, no momento atu- 
al, recursos institucionalizados para a preparação de seus futuros membros (os futuros tradutores e intérpretes) e para sua inserção no mercado de trabalho.

Para além da formação dos profissionais da área (tradutores e intérpretes), o campo disciplinar, ao se consolidar, passa a se preocupar com a formação de pesquisadores, cuja responsabilidade é lançar um olhar crítico sobre a prática - sistematizando-a - e propondo modelos teóricos e metodológicos para a investigação do fenômeno da tradução, em suas mais variadas manifestações. A pesquisa em TILS, em pleno processo de amadurecimento, segue trajetória similar, conforme apresentado a seguir.

\section{Pesquisa em TILS na Pós-Graduação}

Conforme mencionado, a St. Jerome Publishing tomou a iniciativa de veicular um periódico dedicado exclusivamente à pesquisa em TILS, intitulado The Sign Language Translator \& Interpreter. O dois primeiros volumes, Volume 1/2007 e Volume 2/2008 foram organizados por Haesenne e Leeson, membros do 'Institut Libre Marie Haps', Bélgica e 'Centre for Deaf Studies', Dublin, respectivamente. $\mathrm{O}$ fato de o periódico ter sido produzido e disseminado pela St. Jerome reafirma a filiação de pesquisa em TILS ao campo disciplinar Estudos da Tradução. Um dos artigos centrais do Volume 1 é o trabalho de Grbic (2007), intitulado Where do We Come From? What Are We? Where Are We Going? A Bibliometrical Analysis of Writing and Research on Sign Language Interpreting, que faz um estudo bibliométrico da pesquisa sobre Interpretação de Língua de Sinais (ILS), buscando responder as perguntas propostas no título: de onde viemos; $o$ que somos; aonde vamos. ${ }^{11}$ Tais perguntas são indicativas da preocupação identitária de uma área que se vê como emergente, em busca de espaço institucional e acadêmico. A organização do artigo reflete essa preocupação, uma vez que as diversas subse- 
ções desenham a trajetória da pesquisa em ILS: 1 Introdução; 2 Metodologia e corpus; 3 Resultados; 3.1 Panorama dos trabalhos existentes; 3.2 Línguas; 3.3 Tipos de textos; 3.3.1 Periódicos; 3.3.2 Volumes especiais e artigos em volumes especiais; 3.3.3 Teses de doutorado e trabalhos de conclusão de curso; 3.3 .4 Autores; 3.4 Distribuição de temas; 3.5 Desenvolvimento dos temas; 3.5.1 Contexto; 3.5.2 Trabalhos em campos Profissionais.

Uma das subseções que interessa para as reflexões aqui feitas é a subseção 3.3.3 Teses de doutorado e trabalhos de conclusão d curso (ibid., p. 27-29), que descreve o surgimento da pesquisa em ILS em termos de sua disseminação em teses de doutorado, dissertações de mestrado e Trabalhos de Conclusão de Curso, o que sinaliza o crescente interesse por pesquisa sistematizada e institucionalizada em programas pós-graduação, no contexto internacional. Esse interesse é descrito quantitativamente, com base em estudos feitos nos países Alemanha, Áustria, Estados Unidos, Reino Unido e Canadá, em ordem decrescente de produção. O Gráfico 1 mostra a curva ascendente de produção de dissertações (linha vermelho) e teses (linha amarela) entre os anos 1970 e 2005, oferecendo a dimensão quantitativa da pesquisa em ILS no contexto europeu e americano do norte.

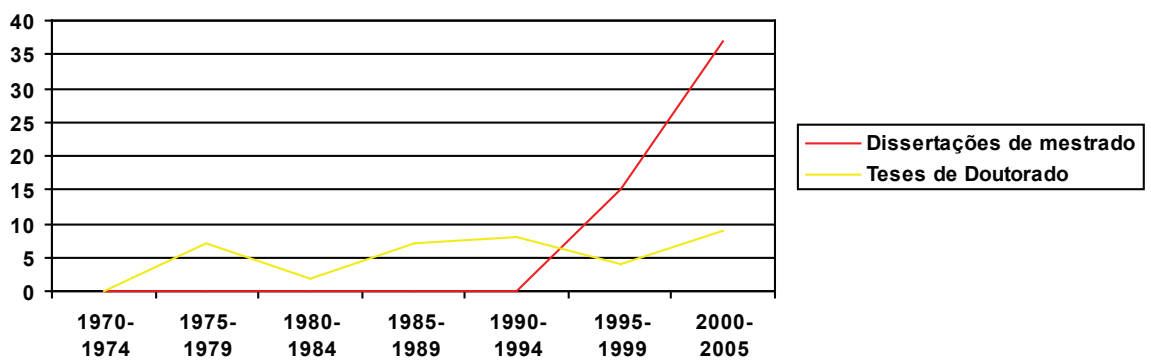

Gráfico 1 - Distribuição de teses e dissertações na linha do tempo 
Grbic (ibid.) chama a atenção para a falta de contato entre ILS e as disciplinas próximas, como Estudos da Tradução e Estudos da Interpretação e afirma a importância de maior integração entre dois campos de estudo que, para ela, são diferenciados. Esse é o ponto em que tomo uma posição diferente, pois o meu argumento é que Estudos da Tradução e Estudos de Interpretação de Língua de Sinais têm - ou podem ter - uma mesma filiação básica, qual seja, o grande campo disciplinar Estudos da Tradução.

Os benefícios da filiação comum podem impactar positivamente o profissional/pesquisador TILS de várias maneiras. Como ilustração, cito o cenário do PPGET. Os objetivos do programa, descritos na seção ‘PROJETO’ do sítio oficial [http://www.pget.ufsc.br/ curso/projeto_pget.php], deixam claro que sua meta principal "é instaurar um pólo institucional amplo, que reunirá todas as atividades no campo da tradução desenvolvidas na Universidade Federal de Santa Catarina" (ênfase minha).

Acredito que é da própria existência desse pólo institucional amplo instaurado que pesquisadores TILS podem inicialmente se beneficiar, tanto em termos de estruturação institucional e acadêmica, como em termos da sistematização do conhecimento construída em linhas de pesquisa definidas, mas passíveis de constante reformulação e ampliação. Chamo a atenção para o adjetivo 'amplo', para mim, representante da política e cultura inclusivas do programa, que busca, entre outras metas (i) contribuir para a expansão e a afirmação do conjunto de atividades ligadas aos Estudos da Tradução no país; (ii) proporcionar o suporte necessário ao desenvolvimento de pesquisas de ponta, através de incentivos aos pesquisadores, professores, estudantes e demais participantes do programa; (iii) promover a criação de novos grupos de pesquisa e fóruns de discussão e de divulgação dos progressos da área; (iv) incentivar a pluralidade de idiomas estudados, estendendo as pesquisas a línguas ainda não atendidas; (v) fortalecer as iniciativas dos outros grupos de pesquisa existentes no cenário científico nacional e mundial, estabelecendo aqui um centro de referência, que 
possa servir como suporte para a ampliação e divulgação dos conhecimentos da área. A própria formulação das metas, nos termos aqui transcritos, evidencia a natureza multifacetada da proposta do PPGET, que convida a exploração de novas fronteiras de pesquisa, em resposta à novas configurações do conhecimento referente a línguas e culturas em contato.

Os benefícios, entretanto, têm mão dupla: pesquisadores em tradução e interpretação de línguas orais podem também ser positivamente impactados pelo contato com pesquisadores em TILS. Como suporte para a sugestão da proficuidade mútua dessa filiação única, (i) cito o exemplo de minha atividade docente na PPGET e meus interesses de pesquisa, que se ampliaram e beneficiaram do contato com a pesquisa em TILS e (ii) contextualizo a discussão no cenário da Universidade Federal de Santa Catarina, especialmente no PPGET.

Com relação ao item (i), saliento os benefícios advindos de dialogar com pesquisa em TILS, no âmbito da PGET. Um exemplo pontual desse diálogo é suficiente para mostrar que a reciprocidade dos benefícios, tanto para o pesquisador de 'tradução e interpretação em língua de sinais', como para o pesquisador de 'tradução em sua dimensão textual' . Durante a disciplina ministrada em 2009.2 - "Tradução e Análise Textual" - tive a presença de alunos/pesquisadoresem-formação cujo interesse de pesquisa era a descrição de Libras, em sua relação com o português brasileiro. Por força dessa presença, busquei interfaces entre o arcabouço teórico-metodológico com que trabalho - a Lingüística Sistêmico-Funcional hallidayana e metodologias de corpus - e a pesquisa em TILS. E acabei me deparando com um pesquisador australiano que aplica a teoria de Halliday ao estudo de línguas de sinais, para investigar o papel da representação visual em AUSLAN (Língua de Sinais Australiana). O autor descreve dados coletados a partir de um inventário de sinais da Auslan produzidos por membros da comunidade surda australiana, sobretudo no que tange a aquisição de Auslan por crianças australianas surdas. Em artigo publicado em 1993, numa coletânea co- 
organizada por M. A. K. Halliday (principal teórico proponente da dimensão metafuncional da lingüística-sistêmico funcional a partir de meados da década de 60), Johnston explora a realização das metafunções lingüísticas em Auslan, expandindo o potencial semiótico da metafunção ideacional, à qual adiciona um eixo espacial, específico de línguas de sinais e utilizando o sistema da Modalidade (que realiza a metafunção interpessoal) como um dos fatores para descrever e explicar a similaridade entre as gramáticas de línguas de sinais. Como resultado de meu diálogo com a pesquisa em TILS, pude perceber que novas interfaces abrem novas possibilidades de investigação. Por exemplo, um tópico que poderia constituir uma pesquisa interessante seria a utilização do mesmo quadro teórico para explorar os procedimentos de tradução da estrutura temática em um corpus bilíngue consistindo de textos autênticos de português e libras, uma vez que as duas línguas apresentam configuração temática bem diferenciada.

Com relação ao item (ii) acima, no âmbito de TILS, os tipos de pesquisa e investigações descritas por Grbic (ibid.) se assemelham às preocupações teóricas e metodológicas manifestadas na pesquisa desenvolvida no âmbito do PPGET. Para fins de cotejamento e comparação, cito alguns dos interesses de pesquisa arrolados pela autora: investigação de contexto de produção e recepção da ILS; questões profissionais; avaliação da qualidade; ética e o papel do intérprete no ambiente sócio-cultural; questões lingüísticas; e aspectos cognitivos. No PPGET, tópicos de pesquisa similares têm sido investigados nas interfaces entre lingüística, literatura, estudos culturais, e estudos multimodais, o que abrem espaço teórico e metodológico para a exploração do contato entre línguas de modalidades diferentes (línguas orais e línguas de sinais). O resultado dessa configuração foi favorecer o acolhimento da pesquisa em TILS, que tem sido desenvolvida e disseminada em dissertações e teses, como mostra o levantamento feito junto ao programa e transcrito abaixo, em ordem alfabética: 
AVELAR, Thaís Fleury. A questão da padronização de sinais nos atores-tradutores surdos do curso de Letras/Libras da UFSC: um estudo descritivo e lexicográfico do sinal "cultura". Dissertação (Mestrado em Estudos da Tradução). Universidade Federal de Santa Catarina. Defesa: 2010.

BAZARUTTI, Viviane. Os processos de tradução para a língua brasileira de sinais no ambiente de ensino do curso de letras libras. Dissertação (Mestrado em Programa de Pós-Graduação em Tradução). Universidade Federal de Santa Catarina. Início: 2008.

NICOLOSO, Silvana. Investigações sobre marcas de gênero na interpretação simultânea sinal-voz da Língua de Sinais Brasileira para a Língua Portuguesa. Tese (Doutorado em Estudos da Tradução). Universidade Federal de Santa Catarina.

NICOLOSO, Silvana. Uma investigação sobre marcas de gênero na interpretação simultânea da Língua de Sinais Brasileira. Dissertação (Mestrado em Pós-Graduação em Estudos da Tradução). Universidade Federal de Santa Catarina, UFSC. Defesa: 2010.

OLIVEIRA, Janine Soares. Tradução de Materiais Acadêmicos para Libras: Estudo do Processo de Formação de Neologismos. Tese (Doutorado em Estudos da Tradução). Universidade Federal de Santa Catarina. Início: 2009.

PEREIRA, Maria Cristina Pires. Os Intérpretes de Língua de Sinais no Ato Tradutório: referenciação de pessoa. Tese (Doutorado em Estudos da Tradução). Universidade Federal de Santa Catarina. Início 2009.

RIGO, Natalia Schleder. Interpretação de musica na Língua de Sinais. Um diálogo de traduções. Dissertação (Mestrado em Estudos da Tradução). Universidade Federal de Santa Catarina. Início: 2009.

SANTOS, Silvana Aguiar. Identidade política dos intérpretes de língua de sinais brasileira. Tese (Doutorado em Estudos da Tradução) - Universidade Federal de Santa Catarina. Início: 2009.

SANTOS, Felipe Tavares. Contando nos dedos: a história dos Interpretes de LIBRAS pro eles mesmos. Dissertação (Mestrado em Estudos da Tradução). Universidade Federal de Santa Catarina. Início: 2009.

SEGALLA, Rimar Romano. Tradução intermodal e intersemiótica/interlinguística: português escrito para a língua de sinais. Dissertação (Mestrado em Estudos da Tradução). Universidade Federal de Santa Catarina. Defesa: 2010. 
SILVA, Letícia Regiane. Tradução de metáforas surdas para a língua portuguesa. Dissertação (Mestrado em Pós-Graduação em Estudos da Tradução). Universidade Federal de Santa Catarina. Início: 2008.

SILVA, Soelge Mendes. Os Limites da Interpretação Simultânea entre Línguas de Diferentes Modalidades: Português e Libras. Dissertação (Mestrado em Estudos da Tradução). Universidade Federal de Santa Catarina. Início: 2009.

SOUZA, Saulo Xavier de. Tradução para a língua brasileira de sinais: descrição de performances observadas no Curso de Letras-Libras. Dissertação (Mestrado em Programa Pós-Graduação em Estudos da Tradução). Universidade Federal de Santa Catarina. Início: 2008.

Com pode ser observado, os temas apontam para tendências consonantes com as pesquisas do contexto internacional: a referenciação de pessoa na interpretação de Libras; identidade política dos intérpretes de língua de sinais; a história dos Interpretes de Libras por eles mesmos; formação de neologismos em Libras; marcas de gênero na interpretação simultânea sinal-voz da Língua de Sinais Brasileira para a Língua Portuguesa; uso do espaço na tradução do português escrito para a língua de sinais brasileira; marcas de gênero na interpretação simultânea da Língua de Sinais Brasileira; tradução de metáforas surdas para a língua portuguesa; tradução para a língua brasileira de sinais no ambiente de ensino do curso de Letras Libras; tradução intermodal e intersemiótica/ interlinguística: português escrito para a língua de sinais; Tradução para a língua brasileira de sinais: descrição de performances observadas no Curso de Letras-Libras; os limites da interpretação simultânea entre línguas de diferentes modalidades; descrição do sinal "cultura" em Libras; e, interpretação de música na língua de sinais brasileira.

Esses trabalhos constituem o marco inicial da pesquisa em Tradução e Interpretação de Língua de Sinais (TILS) na Pós-Graduação brasileira, no âmbito de sua profícua filiação ao campo disciplinar Estudos da Tradução, representado pelo PPGET/UFSC. 


\section{Considerações Finais}

O presente artigo argumentou pela filiação das áreas de pesquisa "Tradução" e "Tradução e Interpretação de Línguas de Sinais" (TILS) e dos profissionais e pesquisadores que nelas atuam ao campo disciplinar Estudos da Tradução (ET), o qual, a partir de seu estabelecimento na década de 70, tem se expandido constantemente em resposta à diversidade da investigação sobre línguas e culturas em contato, inclusive entre modalidades diferentes, como é o caso de línguas orais e línguas de sinais.

Inicialmente, o estudo apresentou e discutiu propostas de mapeamento dos "Estudos da Tradução" no cenário internacional e nacional para, a seguir, mostrar, por meio dos desdobramentos recentes, como a pesquisa em TILS tem sido reconhecida enquanto área de pesquisa no interior dos Estudos da Tradução. Os diferentes mapeamentos foram cotejados e a partir desse cotejamento, foi possível projetar um espaço teórico-metodológico comum, no âmbito do qual foi sugerida a possibilidade do fortalecimento da identidade profissional de pesquisadores, tradutores e intérpretes de línguas de sinais e de língua orais, bem como a possibilidade de uma reflexão informada sobre sua prática.

A revisão da literatura sobre o estado-da-arte da pesquisa em TILS na Pós-Graduação veio por mostrar que o surgimento de teses e dissertações em diferentes programas no contexto internacional atesta o amadurecimento acadêmico da área; mesmo entendendo a especificidade dessa pesquisa, argumentei pela não-fragmentação no interior campo disciplinar Estudos da Tradução. Busquei mostrar que o movimento político de se transformar a diversidade presente na pesquisa sobre TILS em força para o campo disciplinar comum aponta para a possibilidade de descoberta de novas relações e interfaces, reforçando a unidade e a coerência interna. Reconhecendo e valorizando as diferenças, que sugerem a complexidade dos Estudos da Tradução, sugeri que as diversas áreas de pesquisa não pratiquem formas de exclusão mútua e/ou não permitam o apa- 
gamento do que constitui o interesse comum: a tradução, enquanto possibilidade de comunicação lingüística, cultural e política.

A gradual entrada da pesquisa em TILS na agenda dos Estudos da Tradução no Brasil e o movimento estratégico mútuo de aproximação de pesquisadores em TILS e pesquisadores em tradução e interpretação são concretizados, no âmbito da UFSC, por meio da força aglutinadora do Programa de Pós-Graduação em Estudos da Tradução (PPGET). Nesse contexto, foi reafirmada a minha crença na possibilidade de empoderamento dos dois grupos de pesquisadores, quando estrategicamente filiados a um campo disciplinar comum e já estabelecido, cujo objeto de estudo é a tradução, em sua mais ampla acepção e em suas mais variadas manifestações.

\section{Notas}

1. Versão expandida da palestra apresentada no I CONGRESSO NACIONAL DE PESQUISA EM TRADUÇÃO E INTERPRETAÇÃO DE LÍNGUA BRASILEIRA DE SINAIS - TILS 2008.

2. "O tema central deste Congresso foca os intérpretes e tradutores de língua de sinais, profissionais que nos últimos anos, vem se destacando nos cenários acadêmicos em decorrência do alto índice de pesquisadores e acadêmicos surdos no espaço universitário. Por outro lado, apesar da visibilidade lingüística (Língua de Sinais - Português) que está presente na atuação do intérprete e do tradutor, a atenção dispensada a este profissional tem sido um processo árduo e conquistado aos poucos no espaço acadêmico. Este Congresso convoca a necessidade científica para os pesquisadores da área de interpretação e tradução apresentar suas pesquisas que sinalizam para este tema, um espaço de trocas a respeito dos resultados encontrados, de intercâmbio entre as diferentes áreas do conhecimento (educação, tradução e lingüística) e, também, de traçar metas e objetivos de organização profissional e formação para profissionais deste campo" [ http://www.congressotils. cce.ufsc.br/evento.php]. 
3. 'Empoderamento/Empowerment': Termo usado no sentido de evolução do profissional-em-formação dentro do ambiente institucional, ao longo de um continuum de autonomia, desde sua total dependência do professor, até seu status de 'profissional' independente: “(...) expertise can be expected to evolve from novice to journeyman within an institutional setting in direct relationship to progression along the continuum of autonomy, from non-membership in the community of translators, through dyad and small-group interdependence, to teacher-independence (empowerment) as an individual and a team member" (KIRALY, 2000).

4. Este artigo pode ser encontrado na íntegra no site www.scielo.br/delta

5. www.stjerome.co.uk.

6. Visita no dia 08 de maio de 2008.

7. Em inglês, "Signed Language Interpreting".

8. Em inglês, 'Sign Supported' Languages'.

9. Em inglês, 'Sign Language Interpreting'.

10. É curioso observar que metáfora do 'mapa' para delinear os contornos e construir a identidade de um campo disciplinar ainda é utilizada por pesquisadores da atualidade.

11. O estudo foi baseado em 908 textos publicados entre 1970 e 2005 (35 anos divididos em 7 períodos de 5 anos) e teve as seguintes fontes de dados: Annotated Bibliography on Interpretation of Sign Language de autoria de Patrie e Mertz (1997); a versão da Internet da International Bibliography of Sign Language de Guido H. G. Joachim, Siegmund Prillwitz e Thomas Hanke e LiDoc compilado pelo Departamento de Estudos da Tradução da Universidade de Graz. 


\section{Bibliografia}

BAKER, M. The Routledge Encyclopedia of Translation Studies. London, New York, Routledge, 1998.

BRANDÃO, A. L. A invenção do campo disciplinar da Arquitetura: contribuições e contraposições renascentistas. Morus, Campinas, v. 2, n. 2, 2005. p. 65-83 [http://www.arquitetura.ufmg.br/ia/IA7online/artigobrandaook.html].

BRENNAN, M. \& BRIEN, D. MA/Advanced Diploma in British sign Language/ English Interpreting, Deaf Studies Research Unit, University of Durham, course profile. IN: The Translator 1, v.1, 1995.111-28.

GRBIC, N. Where do we come from? What are we? Where are we going? A bibliometrical analysis of writing and research on Sign Language Interpreting, IN: Sign Language Translator and Interpreter 1(1), 2007, 15-51

GUERINI, A \& COSTA, W. Introdução aos Estudos da Tradução - A Tradução e seus aspectos Conceituais. 2008 [http://www.estadosgerais.org/resenhas/tellesbabel.shtml].

FERREIRA-ALVES, F. Uma Experiência de Aprendizagem Colaborativa: Contributos para Repensar o Ensino da Tradução. In: Confluências - Revista de Tradução Científica e Técnica, n. 2, 2005.

[http://74.125.47.132/search?q=cache:xm7UQDaseWYJ:www.confluencias. net $/ \mathrm{n} 2 /$ ferreira-alves. $\mathrm{htm}+$ translator $\% 27 \mathrm{~s}+$ empowerment \&cd $=21 \& \mathrm{hl}=\mathrm{pt}-$ $\mathrm{BR} \& \mathrm{ct}=\mathrm{clnk} \& \mathrm{gl}=\mathrm{br}]$

HOLMES, J. The name and nature and Translation Studies. In VENUTI, L. (Org.). The Translation Studies Reader. Routledge. London, New York, 2000.

JOHNSTON, T. The Realization of the Linguistic Metafunctions in a Sign Language. In Peng, C. C., \& M. A. K. Halliday (Eds.). Language Sciences - Current Research in Functional Grammar, Discourse, and 
Computational Linguistics, with a Foundation in Systemic Theory. 1993, pp. 317-353.

KIRALY, D. A Social Constructivist Approach to Translator Education. Empowerment from Theory to Practice. Manchester, UK: St. Jerome Publishing, 2000.

PAGANO, A \& VASCONCELLOS, M. L. Estudos da tradução no Brasil: reflexões sobre teses e dissertações elaboradas por pesquisadores brasileiros nas décadas de 1980 e 1990. D.E.L.T.A., vol.19, p.1-25, 2003.

SACKS, O. Seeing Voices. New York: Vintage Books, 1991.

SHUTTLEWORTH, M. \& Cowie, M. Dictionary of Translation Studies. Manchester/UK: St. Jerome, 1997.

VASCONCELLOS, M.L. \& BARTHOLAMEI, L. J. Estudos da Tradução I. 2008. [http://www.libras.ufsc.br/hiperlab/avalibras/moodle/prelogin/adl/fb/logs/ Arquivos/textos/estudos_da_traducao/Estudos_Traducao_I.pdf]. ISBN: 978-8560522-19-4.

VENUTI, L. (Org.). The Translation Studies Reader. Routledge. London, New York, 2000.

WILLIAMS, J \& CHESTERMAN, A. The Map: a beginner's guide to doing research in translation studies. Manchester: St. Jerome Publishing, 2002.

The Sign Language Translator and Interpreter (SLTI), Volume 1, Issue 1, 2007, St. Jerome Publishing, Manchester, UK - ISSN 1750-3981). 
